\title{
Bridging Photonics and Optoelectronics Curriculum for the Solar Photovoltaic and LED Industries
}

\author{
Yu-Shan Su${ }^{1}$ and Han-Chao Chang ${ }^{2}$ \\ ${ }^{1}$ Department of Industrial Education, National Taiwan Normal University, Taipei 106, Taiwan \\ ${ }^{2}$ Instrument Technology Research Center, National Applied Research Laboratories, Hsinchu 300, Taiwan \\ Correspondence should be addressed to Han-Chao Chang; roman@narlabs.org.tw
}

Received 22 May 2014; Revised 11 August 2014; Accepted 12 August 2014; Published 28 August 2014

Academic Editor: Chao-Rong Chen

Copyright ( 2014 Y.-S. Su and H.-C. Chang. This is an open access article distributed under the Creative Commons Attribution License, which permits unrestricted use, distribution, and reproduction in any medium, provided the original work is properly cited.

\begin{abstract}
The gap between learning courses and practical demands has existed in Taiwanese solar photovoltaic and LED industries; therefore, this study attempts to analyze the existing curriculum design of universities. This study collected the current 103 course programs from all optoelectronics-related departments in Taiwanese 36 colleges and universities and sorted these curriculums by three domains of education objectives theory. This theoretical framework was verified on the basis of samples from 150 Taiwanese industrial experts and 354 optoelectronics-related undergraduates and postgraduates. We found that the levels of correlation among the independent variables including cognitive, affective, and skill-based domains and the dependent variable employability are all positively related to each other. We also found the currently curriculum design in Taiwanese universities rarely fit into theory of education objectives from the results of multiple regression analysis. Industrial and student's group also have few consistent ideas on courses within the curriculum. Finally in order to bridge the gap between learning and practical application, the study provides an idea on curriculum design and suggests that curriculum review should be executed by industrial experts to confirm the courses related to the employability.
\end{abstract}

\section{Introduction}

Climate change and energy shortage is one of the world's greatest challenges of the 21st century. Most countries treat renewable energy and energy conservation as the infrastructures for their sustainable development of the environment. Furthermore, the top priority of their national technology is the enhancements of low-carbon energy. In recent years, Taiwan has also followed this trend, investing plenty of assets into the solar photovoltaic and LED industries and constantly expanding production capacity. The integration of whole supply chains has matured.

However, like other export-oriented industries the cost of production, product yield, and employees' professional ability still affect the development of these two industries. The most common complaint from many local CEO's and managers is the insufficient professional ability of both the undergraduates and postgraduates from the universities, and that this is the primary reason for lagging behind the United States and Germany $[1,2]$.
Therefore, this study used the educational theory framework from Bloom and his colleagues to examine the existing curriculum design from undergraduate and postgraduate programs. Hoping the defects of the current curriculum design could be discovered. Next, the study attempted to formulate a better course program that will lead industrial requirements and photoelectric department's curriculum [3$6]$.

\section{Literature Review}

The theory of education objectives has been established by Bloom since 1956 [7]. Cognitive domain was the initial concept he devoted. Educational objectives are the goals set by educational establishments, which concentrates on people's studies. He emphasizes that, within the contents of the curriculum of courses, lecturers have to achieve their teaching mission and students have to realize the learning goals synchronously. The checkpoints or exams 
include knowledge, skills, and abilities or attitudes after completing the assigned course [8]. After few years, affective and skill-based domain were came up by Krathwohl and Bloom [9]. Therefore, cognitive, affective, and skill-based (also called psychomotor) are three domains in their theory. The following is a summary of the three domains within education theory and education objectives.

\section{(i) Cognitive Domain}

Objective Scope. Encompasses memory, thinking, recognition, application, and so forth about people, events, and things.

Objective Hierarchy. Krathwohl and Bloom [9] divide the cognitive domain into "basic knowledge memory" division and "intelligence and skills" division [7]. Basic knowledge memory refers to the memory of various forms of information, where such information tends to have a standard answer. However, "intelligence and skills" division emphasizes thinking abilities of criticalness, introspection, and problem-solving.

In addition, the major hierarchies in the cognitive domain are divided into six levels, the sequential order is remember, understand, apply, analyze, evaluate, and create [10].

(1) Remember: to remember a host of information in the teaching process, it often requires the learner to memorize the important information from the content of the textbook.

(2) Comprehension: this determines the meaning of the teaching information, including verbal, written, and graphic.

(3) Application: to apply the learned knowledge in a new scenario.

(4) Analysis: to analyze the elements that make up knowledge or information, bringing a clearer hierarchy correlation.

(5) Evaluation: to render a value judgment based on specific standards.

(6) Synthesis: to streamline all elements in one to form innovative or comprehensive works.

\section{(ii) Affective Domain}

Objective Scope. Encompasses attitude, emotion, and appreciation of the teaching objectives, beliefs, and the like.

Objective Hierarchy. The affective is a form of mental state or emotional tendency, together with positive and negative reactions. Therefore, the affective domain is mostly abstract in expression of the means of educational objectives. Krathwohl and Bloom [9] divided affective domain into five levels, where the classification is a continuous and spiral structure. The lower levels indicate simplistic, tangible, and unique behaviors. The higher levels contain the more common, abstract, and generalized behaviors. The meanings of the five levels are described as follows [11].

(1) Receiving: to show concern for specific matters or activities.
(2) Responding: to react to matters by a form of participation.

(3) Valuing: to express approval or opposition to specific matters through positive or negative attitudes.

(4) Organizing: the ability to organize and determine importance when faced with multiple values that require judgment.

(5) Characterizing: the students handle the matter based on the values they have learned and also internalize the behavior into their personal characteristics.

\section{(iii) Skill-Based Domain}

Objective Scope. It focuses on the visible movements or behaviors.

Objective Hierarchy. Krathwohl [11] had not designed the objective hierarchy for the skill-based domain in 1969. However many scholars proposed an objective hierarchy. For example, since 1966, Simpson did divide the skill-based domain into seven levels including perception, set, guided response, mechanism, complex over-response, adaptation, and origination [12,13]. Later on 2000, Anderson et al. [10] issued a revision of Bloom's taxonomy of educational objectives and included the skill-based domain in this book.

In addition, the Taiwanese scholars [14] collected literature and experts' opinions; they thought that "employability" is an effective ability to join work matters. They also found that the interpretation model formulated effectively interprets the relationship between solar enterprises' expectations and students' employability. Furthermore, some scholars emphasized that employability has to combine knowledge, skills, and attitudes together and then assist people to learn or work continually $[1,15,16]$. This study sorts the characteristics from literature into Table 1.

\section{Methodology}

Based on the above, the following research framework (Figure 1) is proposed and the causal relationship between each domain of educational objectives theory and employability is hypothesized. The theory of education objectives of Bloom and Krathwohl [7, 10, 11], which includes cognitive, affective, and skill-based domains, is employed in the current study as independent variables. Employability $[10,14,15]$ is used as a dependent variable.

3.1. Research Design and Methodology. This study collected the current 103 course programs from all optoelectronicsrelated departments in Taiwanese 36 colleges and universities and asked about the level of importance related to employability for respondents. Based on the course content and program goal, this study sorted these curriculums by three domains of education objectives theory $[7,10,11]$. Multiple linear regression analysis was employed to test the capability of each course program to predict employability. It is worth noting that some courses have one more property and cross domains simultaneously, and some names of course are approximate. 
TABle 1: Three dimensions of employability.

\begin{tabular}{|c|c|c|c|}
\hline \multirow{2}{*}{$\begin{array}{l}\text { Knowledge } \\
\text { The use of mathematical } \\
\text { logic }\end{array}$} & \multirow{2}{*}{$\begin{array}{l}\text { Skill } \\
\text { Work independently }\end{array}$} & \multicolumn{2}{|c|}{ Attitude } \\
\hline & & Physical and mental traits & Frustration tolerance \\
\hline Language expression & Use of technology & Adapt to the changes & Interpersonal social skills \\
\hline Cultural learning & Solve the problem & Emotional management & Teamwork \\
\hline $\begin{array}{l}\text { Obtain and use of } \\
\text { information }\end{array}$ & Creativity and critical thinking & Responsibility & Communication and coordination \\
\hline \multirow[t]{2}{*}{$\begin{array}{l}\text { Know and understand } \\
\text { multiculturalism }\end{array}$} & Decision & Active learning & Respect and mutual trust \\
\hline & & Career planning & Participation in public affairs \\
\hline
\end{tabular}

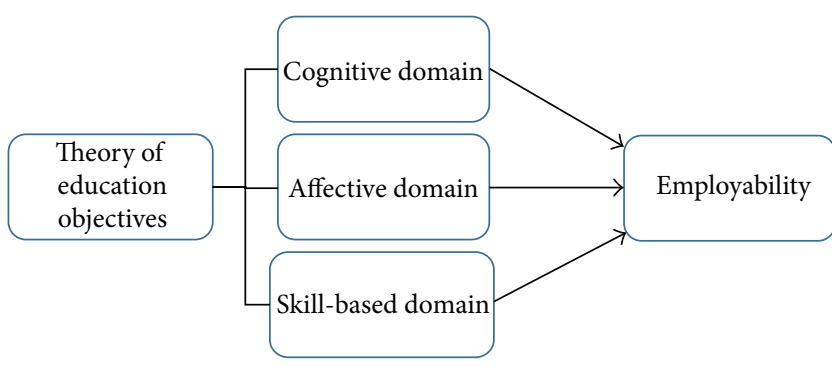

Figure 1: Framework of study.

The study initially implemented the expert interview method [17] and invited professionals from universities, Taiwan's solar optoelectronics industry, and the LED industry. By relying on expert interviews (November 2013, 10 experts), the study was able to sort the trends and human resource planning along with the demands of the solar optoelectronics and LED industry for the future. Most of the experts thought the disparity between university course programs and career demand is a wide gap. Experts emphasized prototype production, patent application [18], foreign language, and oral expressiveness as the foundations for employability; however the weighing of pure academy courses is too much on common curriculum design.

Next, a cross-sectional, descriptive, and inferential research study design was used in the current study. Purposive sampling techniques were employed, focusing on Taiwanese solar optoelectronics and LED industries. The contacts (including telephone numbers and email addresses) were obtained from respective firms' websites, as well as through personal relationships. Following initial contact and agreement, the questionnaire was sent via email. Frequent follow-up calls were made after one week if the questionnaire was not returned. Inclusion criteria included (1) college/university students; (2) industry operators. Each participant supplied written consent after being fully informed of the study and completed the self-administered questionnaire at his or her convenience.

To assess content validity, three experts from expert interviewing completed and scored the first draft of the questionnaire. A 5-point Likert scale was used for this process $(1=$ strongly unacceptable (delete), $2=$ unacceptable (significantly revise), $3=$ acceptable (partial amendment needed), $4=$ acceptable (detail needs amending), and $5=$ acceptable (no amendment)). All questions obtained scores of 4 or 5 after amendments were made, leading us to consider the questionnaire possessed acceptable content validity.

A total of 371 questionnaires were distributed to college/university students at optoelectronics-related departments, and 354 were retrieved (95.4\%); after removing 16 nonvalid questionnaires, 338 were available for analysis (Table 2). The schools were represented from all over Taiwan Island, including National Taiwan University (Taipei), National Taiwan Normal University (Taipei), Ming Chuan University (Taipei), Yuan Ze University (ChungLi), Chung Hwa University (HsinChu), and Nan Tai University of Technology (Tainan). Meanwhile, 163 questionnaires were distributed to industry senior staff and 150 were returned (92.0\%) from the LED, solar optoelectronics, and general industries (Table 3). The total number of questionnaires returned was 504 .

\section{Research Findings}

The study divided the sample data into two segments, comprised of the college/university students and the industry operators. The tools and methods of statistical analysis used included sample demographic data, reliability analysis, product-moment correlation analysis, and multiple regression analysis and performed with SPSS 20.0.

4.1. Reliability Analysis. A Cronbach's $\alpha$ value was used to measure reliability and inner consistency within the same dimension. According to Anastasi [19] and McKinley et al. [20], a value between 0.7 and 0.98 can be judged as having high reliability, while a value under 0.6 is unacceptable for exploratory research. In this study, the scores were in the range of 0.939 to 0.961 (Table 4 ) for the universities sample and 0.884 to 0.976 (Table 5) for the industries sample.

4.2. Product-Moment Correlation Analysis. Coefficient of correlation was used to express the correlation direction and level of two variables. 0.6 to 1.00 are highly correlated; 0.40 to .59 are intermediately correlated; and under 0.40 is low correlation. The study adopted product-moment correlation $r$ to analyze the level of correlation of two variables belonging to the same tendency scale or equal measurement scale. 
TABLE 2: Demographic data from universities respondents.

\begin{tabular}{|c|c|c|c|}
\hline Variable & Scale & Number & $\%$ \\
\hline \multirow{2}{*}{ Gender } & Male & 257 & $76 \%$ \\
\hline & Female & 81 & $24 \%$ \\
\hline \multirow{2}{*}{ University } & National & 124 & $36.7 \%$ \\
\hline & Private & 214 & $63.3 \%$ \\
\hline \multirow{3}{*}{ School } & Normal University & 234 & $69.2 \%$ \\
\hline & University of Science and Technology & 92 & $27.2 \%$ \\
\hline & University of Education & 12 & $3.6 \%$ \\
\hline \multirow{5}{*}{ Grade } & Freshman & 5 & $1.5 \%$ \\
\hline & Sophomore & 119 & $35.2 \%$ \\
\hline & Junior & 156 & $46.2 \%$ \\
\hline & Senior & 47 & $12.1 \%$ \\
\hline & Postpone & 17 & $5 \%$ \\
\hline \multirow{5}{*}{ Department } & Electrical engineering & 217 & $64.2 \%$ \\
\hline & Dep. of Chemical and Materials Engineering & 6 & $1.8 \%$ \\
\hline & Dep. of Electro-Optical Science and Technology & 108 & $32 \%$ \\
\hline & Dep. of Environmental Engineering & 1 & $0.3 \%$ \\
\hline & Other & 6 & $1.8 \%$ \\
\hline
\end{tabular}

TABle 3: Demographic data from industries respondents.

\begin{tabular}{|c|c|c|c|}
\hline Variable & Scale & Number & $\%$ \\
\hline \multirow{2}{*}{ Gender } & Male & 134 & $89.3 \%$ \\
\hline & Female & 16 & $1.7 \%$ \\
\hline \multirow{4}{*}{ Age } & $25-35$ & 75 & $50 \%$ \\
\hline & $36-45$ & 48 & $32 \%$ \\
\hline & $46-55$ & 22 & $14.7 \%$ \\
\hline & Older then 56 & 5 & $3.3 \%$ \\
\hline \multirow{3}{*}{ Job title } & Person in charge & 3 & $2 \%$ \\
\hline & Department Manager & 16 & $10.7 \%$ \\
\hline & Other & 131 & $87.3 \%$ \\
\hline \multirow[t]{2}{*}{ Type of company } & $\begin{array}{l}\text { Small- and medium-sized enterprises } \\
\text { (less than capital 8,000 ten thousand) }\end{array}$ & 57 & $38 \%$ \\
\hline & $\begin{array}{l}\text { Large enterprises } \\
\text { (more than capital 8,000 ten thousand) }\end{array}$ & 93 & $62 \%$ \\
\hline \multirow{3}{*}{ Industry } & Solar photovoltaic & 85 & $56.7 \%$ \\
\hline & LED/lighting & 11 & $7.3 \%$ \\
\hline & Other related & 54 & $36 \%$ \\
\hline
\end{tabular}

TABLE 4: Reliability analysis-universities sample.

\begin{tabular}{lccc}
\hline Dimensions & Number & Cronbach's $\alpha$ & Mean \\
\hline Cognitive & 43 & .955 & 3.89 \\
Affective & 25 & .961 & 3.845 \\
Skill-based & 26 & .956 & 3.836 \\
Employability & 15 & .939 & 4.224 \\
Overall reliability & 119 & .982 & 3.907 \\
\hline
\end{tabular}

In the college/university segment (Table 6), the levels of correlation among the four domains of cognitive, affective, skill-based, and employability are all positively associated
TABLE 5: Reliability analysis-industry sample.

\begin{tabular}{lccc}
\hline Dimensions & Number & Cronbach's $\alpha$ & Mean \\
\hline Cognitive & 43 & .947 & 4.541 \\
Affective & 25 & .930 & 4.500 \\
Skill-based & 26 & .884 & 4.483 \\
Employability & 15 & .925 & 4.450 \\
Overall reliability & 119 & .976 & 4.505 \\
\hline
\end{tabular}

with each other. The level of correlation shows intermediate and high correlation. Cognitive is highly correlated to 
TABLE 6: Correlation analysis-universities sample.

\begin{tabular}{|c|c|c|c|c|c|c|}
\hline Dimensions & Mean & s.d. & Cognitive & Affective & Skill-based & Employability \\
\hline Cognitive & 3.89 & .473 & 1 & & & \\
\hline Affective & 3.84 & .530 & .817 & 1 & & \\
\hline Skill-based & 3.84 & .623 & .709 & .760 & 1 & \\
\hline Employability & 4.22 & .581 & .481 & .501 & .466 & 1 \\
\hline
\end{tabular}

TABLE 7: Correlation analysis-industry sample.

\begin{tabular}{|c|c|c|c|c|c|c|}
\hline Dimensions & Mean & s.d. & Cognitive & Affective & Skill-based & Employability \\
\hline Cognitive & 4.555 & .4581 & 1 & & & \\
\hline Affective & 4.5 & .4435 & .937 & 1 & & \\
\hline Skill-based & 4.483 & .4274 & .884 & .896 & 1 & \\
\hline Employability & 4.449 & .5316 & .522 & .513 & .482 & 1 \\
\hline
\end{tabular}

affective (0.817) and the skill-based (0.709) domain individually. This variable also shows intermediate correlation to employability (0.481). Affective is highly correlated to skillbased (0.760) and intermediate correlation to employability (0.501). The skill-based domain also shows intermediate correlation to employability (0.466). The findings indicate a certain level of correlations among the four domains. Namely, the hypothesis of this study, the causal relationship between educational goal of curriculum and employability, was supported in the university segment.

In the industry segment (Table 7), the levels of correlation among the four domains of cognitive, skill-based, affective, and employability are also positively associated to each other with highly significant correlation. Cognitive is highly correlated to affective $(0.937)$ and the skillbased (0.884) domain individually. This variable also shows intermediate correlation to employability (0.522). Affective is highly correlated to skill-based (0.896) and intermediately correlated to employability (0.513). The skilled-based domain also shows intermediate correlation to employability (0.482). The findings indicate a certain level of correlations among the four domains. Namely, the hypothesis of this study, the causal relationship between educational goal of curriculum and employability, was supported in the industry segment.

\section{Multiple Regression Analysis}

Multiple regression was employed to account for (predict) the variance in an interval dependent based on linear combinations of interval, dichotomous, or dummy independent variables. Multiple regression can establish that a set of IVs explains a proportion of the variance in a DV at a significant level (through a significance test of $R^{2}$ ) and can establish the relative predictive importance of independent variables by comparing beta weights [21].

The multiple regression equation takes the form $y=$ $b_{1} X_{1}+b_{2} X_{2}+\cdots+b_{n} X_{n}+\varepsilon$. The $b$ 's are the regression coefficients, representing the amount the dependent variable $y$ changes when the corresponding independent variable changes by 1 unit. The $\varepsilon$ is the constant (so called "residual"), where the regression line intercepts the $y$-axis, representing the amount the dependent $y$ will be when all the independent variables are zero. The standardized versions of the $b$ coefficients are the beta weights, and the ratio of the beta coefficients is the ratio of the relative predictive power of the independent variables. Associated with multiple regressions is $R^{2}$, the multiple correlations, which is the percentage of the variance in the dependent variable, explained collectively by all of the independent variables.

Multiple linear regression attempts to model the relationship between two or more explanatory variables and a response variable by fitting a linear equation into observed data $[21,22]$. The estimates ( $b$ coefficients, $F$ test, and adjusted $R^{2}$ ) can be used to construct a prediction equation and generate predicted scores of a variable for further analysis. The $P$ value in regression analysis decided whether the correct or causal relationship was established. Generally, the value of (.05) is an accepted point to reject the null hypothesis. It can say with a $95 \%$ probability of being correct that the variable is having some effect, assuming the model is specified correctly with a $P$ value of 5\%; namely, the lower the $P$ value in the result of regression analysis, the higher the correction of assuming the model [22].

5.1. Multiple Regression Analysis on Various Curriculum Domains to Employability. First, the demographic data, such as gender, university type, school, grade, and department, were employed from the university segment as independent variables, while employability was set as a dependent variable. Results (see Table 8) indicate that the demographic data accounted for $7.8 \%$ of the variance in employability $\left(R^{2}=\right.$ $0.072, F=5.143, P<0.001)$. Evaluation of the regression coefficients indicates that gender $(b=0.185, P<0.005)$, university type $(b=0.273, P<0.001)$, school $(b=-0.234$, $P<0.01)$, and department $(b=-0.100, P<0.1)$ were the statistically significant components of model 1 . However, the grade of university sample showed no significance for mode 1 .

Second, the demographic data and cognitive domain from education objectives theory were employed from the university segment as independent variables, while employability was set as a dependent variable. Results (see Table 8) 
TABLE 8: Multiple regression analysis-three-domain curriculum on employability (university sample).

\begin{tabular}{|c|c|c|c|c|}
\hline \multirow{2}{*}{ Variable } & \multicolumn{4}{|c|}{ Employability } \\
\hline & $\beta$ estimate (standard error) & $\beta$ estimate (standard error) & $\beta$ estimate (standard error) & $\beta$ estimate (standard error) \\
\hline Gender & $.185(.072)^{*}$ & $.167(.061)^{* *}$ & $.167(.061)^{* *}$ & $.180(.063)^{*}$ \\
\hline University type & $.273(.074)^{* * *}$ & $.041(.066)$ & $.044(.066)$ & $.083(.067)$ \\
\hline School studying & $-.234(.073)^{* *}$ & $-.260(.062)^{* * *}$ & $-.262(.062)^{* * *}$ & $-.261(.064)^{* * *}$ \\
\hline Grade & $.011(.042)$ & $.003(.035)$ & $-.001(.035)$ & $.006(.036)$ \\
\hline Department & $-.100(.036)^{+}$ & $-.108(.031)^{* * *}$ & $-.115(.030)^{* * *}$ & $-.128(.031)^{* * *}$ \\
\hline Cognitive & & $.269(.100)^{+}$ & $.274(.096)^{+}$ & $.125(.067)^{+}$ \\
\hline Affective & & & $.317(.097)^{* *}$ & $.352(.087)^{* * *}$ \\
\hline Skill-based & & & & $.629(.060)^{* * *}$ \\
\hline$\overline{R^{2}}$ & .072 & .342 & .335 & .302 \\
\hline Adjusted $R^{2}$ & .058 & .326 & .321 & .290 \\
\hline$F$ & $5.143^{* * *}$ & $21.404^{* * *}$ & $23.788^{* * *}$ & $23.909^{* * *}$ \\
\hline
\end{tabular}

Note: ${ }^{+} P<0.100,{ }^{*} P<0.050,{ }^{* *} P<0.010$, and ${ }^{* * *} P<0.001$.

indicate that the cognitive domain accounted for $34.2 \%$ of the variance in employability $\left(R^{2}=0.342, F=21.404\right.$, $P<0.001)$. Evaluation of the regression coefficients indicates that gender $(b=0.167, P<0.01)$, school $(b=-0.260$, $P<0.001)$, department $(b=-0.109, P<0.001)$, and cognitive $(b=0.269, P<0.1)$ were the statistically significant components of model 2. However, the university type and grade from the university sample showed no significance for mode 2 .

Third, the demographic data and cognitive and affective domain from education objectives theory were employed from the university segment as independent variables, while employability was set as a dependent variable. Results (see Table 8) indicate that the affective domain accounted for $33.5 \%$ of the variance in employability $\left(R^{2}=0.335, F=\right.$ $23.788, P<0.001)$. Evaluation of the regression coefficients indicate that gender $(b=0.167, P<0.01)$, school $(b=$ $-0.262, P<0.001)$, department $(b=-0.115, P<0.001)$, cognitive $(b=0.274, P<0.1)$, and affective $(b=0.317, P<$ 0.01 ) were the statistically significant components of model 3. However, the university type and grade from university sample showed no significance for mode 3 .

Fourth, the demographic data and three domains from education objectives theory were employed from the university segment as independent variables, while employability was set as a dependent variable. Results (see Table 8) indicate that the skill-based accounted for $30.2 \%$ of the variance in employability $\left(R^{2}=0.302, F=23.7909, P<0.001\right)$. Evaluation of the regression coefficients indicates that gender $(b=0.180, P<0.05)$, school $(b=-0.261, P<0.001)$, department $(b=-0.128, P<0.001)$, cognitive $(b=0.125$, $P<0.1)$, affective $(b=0.352, P<0.001)$, and skill-based ( $b=0.629, P<0.001)$ were the statistically significant components of model 4 . However, the university type and grade from university sample still showed no significance for mode 4.

Therefore, the hypothesis, the causal relationship between each domain of educational objectives theory and employability were supported by the results of multiple regression analysis from the university segment. In the manifestation of the coefficients, gender, university type, school, and department from the demographic data was associated with the variable employability.

In addition, the demographic data, such as gender, age, business type, and industry type were employed from the industry segment as independent variables, while employability was set as a dependent variable. Results (see Table 9) indicate that the demographic data accounted for $5.7 \%$ of the variance in employability $\left(R^{2}=0.056, F=1.739\right)$. Evaluation of the regression coefficients indicate that business type $(b=-0.231, P<0.05)$ and industry type $(b=0.059$, $P<0.05)$ were the statistically significant components of model 1. However, gender, age, and title from industry sample show no significance for mode 1 .

Second, the demographic data and cognitive domain from education objectives theory were employed from the industry segment as independent variables, while employability was set as a dependent variable. Results (see Table 9) indicate that the cognitive domain accounted for $32.3 \%$ of the variance in employability $\left(R^{2}=0.323, F=11.351, P<\right.$ $0.001)$. Evaluation of the regression coefficients indicates that business type $(b=-0.170, P<0.1)$, industry type $(b=0.06$, $P<0.01)$, and cognitive $(b=0.630, P<0.001)$ were the statistically significant components of model 2. However, gender, age, and title from the industry sample showed no significance for mode 2 .

Third, the demographic data and cognitive and affective domain from education objectives theory were employed from the industry segment as independent variables, while employability was set as a dependent variable. Results (see Table 9) indicate that the affective domain accounted for $32.4 \%$ of the variance in employability $\left(R^{2}=0.324, F=\right.$ 9.722, $P<0.001)$. Evaluation of the regression coefficients indicate that business type $(b=-0.174, P<0.1)$, industry type $(b=0.058, P<0.05)$, and cognitive $(b=0.506$, $P<0.05)$ were the statistically significant components of model 3. However, gender, age, title, and affective domain from the industry sample showed no significance for mode 3. 
TABLE 9: Multiple regression analysis-three-domain curriculum on employability (industry sample).

\begin{tabular}{lcccc}
\hline \multirow{2}{*}{ Variable } & & \multicolumn{3}{c}{ Employability } \\
& $\beta$ estimate (standard error) & $\beta$ estimate (standard error) & $\beta$ estimate (standard error) & $\beta$ estimate (standard error) \\
\hline Gender & $-.030(.143)$ & $.084(.122)$ & $.072(.125)$ & $.071(.126)$ \\
Age & $.009(.057)$ & $.069(.050)$ & $.070(.050)$ & $.070(.050)$ \\
Title & $-.076(.090)$ & $-.003(.077)$ & $.000(.077)$ & $.000(.080)$ \\
Business type & $-.231(.107)^{*}$ & $-.170(.092)^{+}$ & $-.174(.092)^{+}$ & $-.174(.093)^{+}$ \\
Industry type & $.059(.026)^{*}$ & $.060(.022)^{* *}$ & $.058(.023)^{*}$ & $.058(.023)^{*}$ \\
Cognitive & & $.630(.084)^{* * *}$ & $.506(.246)^{*}$ & $.505(.261)^{+}$ \\
Affective & & & $.133(.249)$ & $.132(.271)$ \\
Skill-based & .057 & & .324 & $.003(.211)$ \\
\hline$R^{2}$ & .024 & .323 & .291 & .324 \\
Adjusted $R^{2}$ & 1.739 & .294 & $.722^{* * *}$ & .286 \\
$F$ & & $11.351^{* * *}$ & & $8.447^{* * *}$ \\
\hline
\end{tabular}

Note: ${ }^{+} P<0.100,{ }^{*} P<0.050,{ }^{* *} P<0.010$, and ${ }^{* * *} P<0.001$.

Fourth, the demographic data and three domains from education objectives theory were employed from the industry segment as independent variables, while employability was set as a dependent variable. Results (see Table 9) indicate that skill-based accounted for $32.4 \%$ of the variance in employability $\left(R^{2}=0.324, F=8.447, P<0.001\right)$. Evaluation of the regression coefficients indicates that business type $(b=$ $-0.174, P<0.1)$, industry $(b=0.058, P<0.05)$, and cognitive $(b=0.505, P<0.1)$ were the statistically significant components of model 4 . However, gender, age, title, affective, and skill-based from the industry sample still showed no significance for mode 4 .

Therefore, the hypothesis, the causal relationship between cognitive domain and employability, is supported by the results of multiple regression analysis from the industry university segment. Both the affective and skill-based domain of educational objectives theory have no association with employability in this study. In the manifestation of the coefficients, the business type and industry type from the demographic data were associated with the variable employability.

5.2. Multiple Regression Analysis on Courses with Cognitive Domain to Employability. Results (see Table 10) show that the course program in cognitive domain accounted for $70.4 \%$ of the variance in employability $\left(R^{2}=0.704, F=6.721, P<\right.$ 0.001 ), with a significant interpretability from the university segment. Evaluation of the regression coefficients indicates that there were only 13 courses, LED Engineering Introduction $(b=0.128, P<0.05)$, Solar Energy System Application Introduction $(b=0.162, P<0.01)$, Semiconductor Memory $(b=-0.097, P<0.05)$, Optoelectronics Engineering Introduction $(b=-0.108, P<0.05)$, Optoelectronics Technology Introduction $(b=0.135, P<0.05)$, Energy Engineering Introduction $(b=-01.67, P<0.05)$, New Energy Introduction $(b=0.113, P<0.05)$, Electromagnetic Optics $(b=0.243, P<0.001)$, Electronics $(b=0.146$, $P<0.01)$, Physics of Semiconductor Devices $(b=0.201$, $P<0.001)$, Semiconductor Sense Devices $(b=0.111, P<$ $0.1)$, Polymer Material and Devices $(b=-0.135, P<0.1)$, and Calculated Optoelectronic Devices $(b=0.018, P<0.05)$ that were statistically significant components of the model.

Results (see Table 11) show that the course program in cognitive domain accounted for $61.5 \%$ of the variance in employability $\left(R^{2}=0.615, F=3.937, P<0.001\right)$, with a significant interpretability from the industry segment. Evaluation of the regression coefficients indicate that there were only 8 courses, Solar Energy System Application Introduction $(b=0.225, P<0.05)$, Semiconductor Memory $(b=$ $-0.451, P<0.05)$, Optoelectronics Technology Introduction $(b=0.230, P<0.1)$, Recent Optoelectronics $(b=0.222$, $P<0.1)$, Lighting Engineering Introduction $(b=0.426$, $P<0.05)$, Optoelectronics Introduction $(b=0.321, P<$ $0.05)$, Material of Organic Optic $(b=-0.399, P<0.1)$, and Subject of Optoelectronic Engineering $(b=0.825, P<0.05)$ that were statistically significant components of the model. Thus, industry and students group have a consistent idea on 3 courses within the course program in cognitive domain.

5.3. Multiple Regression Analysis on Skill-Based Domain Course to Employability. Results (see Table 12) show that the course program in skilled-based domain accounted for $69.3 \%$ of the variance in employability $\left(R^{2}=0.693, F=7.97\right.$, $P<0.001$ ), with a significant interpretability from the university segment. Evaluation of the regression coefficients indicate that there were only 10 courses within 35 courses, Design of Solar Power and Lighting $(b=0.120, P<0.05)$, Optoelectronic Nanometer Structure $(b=0.135, P<0.05)$, Optoelectronic Circuit Application $(b=0.154, P<0.1)$, Solar Energy Technical $(b=-0.092, P<0.1)$, Process of Semiconductor Devices $(b=-0.152, P<0.1)$, Optoelectronic Storage Technical $(b=0.135, P<0.01)$, Semiconductor Circuit Package $(b=0.151, P<0.01)$, Optoelectronic Testing $(b=-0.055, P<0.05)$, Optoelectronic Interference $(b=0.015, P<0.05)$, and Light-Spot Testing $(b=0.002$, $P<0.01)$ that were statistically significant components of the model.

Results (see Table 13) show that the course program in skilled-based domain accounted for $59.6 \%$ of the variance 
TABLE 10: Multiple regression analysis-cognitive domain curriculum on employability (university sample).

\begin{tabular}{|c|c|}
\hline Program name & $\begin{array}{c}\text { Employability } \\
\beta \text { estimate } \\
\text { (standard error) }\end{array}$ \\
\hline LED Engineering Introduction & $.128(.051)^{*}$ \\
\hline LED Lighting Application Introduction & $-.070(.051)$ \\
\hline Solar Power System Introduction & $.162(.056)^{* *}$ \\
\hline Battery of Solar Power Introduction & $-.120(.073)$ \\
\hline Theory of semiconductor luminous & $.027(.055)$ \\
\hline Semiconductor Memory & $-.097(.048)^{*}$ \\
\hline FPD Introduction & $.017(.055)$ \\
\hline Optoelectronics Engineering Introduction & $-.108(.048)^{*}$ \\
\hline Optoelectronics Technical Introduction & $.039(.055)$ \\
\hline Optoelectronics Technology Introduction & $.135(.054)^{*}$ \\
\hline Energy Engineering Introduction & $-.167(.052)^{*}$ \\
\hline Theory of Optoelectronics Instrument & $-.059(.055)$ \\
\hline Recent Optoelectronics Introduction & $.061(.055)$ \\
\hline Fourier Optics Introduction & $-.070(.053)$ \\
\hline New Energy Introduction & $.113(.046)^{*}$ \\
\hline Lighting Engineering Introduction & $-.033(.052)$ \\
\hline Optoelectronics & $-.037(.051)$ \\
\hline Wave Optic & $.013(.049)$ \\
\hline Semiconductor Laser & $.082(.062)$ \\
\hline Semiconductor Optic & $.069(.061)$ \\
\hline Electromagnetics Optic & $.243(.058)^{* * *}$ \\
\hline Optoelectronics System & $.045(.055)$ \\
\hline Optoelectronics Introduction & $.074(.050)$ \\
\hline Innovation of Optoelectronics & $.025(.048)$ \\
\hline Geometrical Optic & $-.017(.046)$ \\
\hline Electronics & $.146(.045)^{* *}$ \\
\hline Electric Circuitry & $-.071(.045)$ \\
\hline Physics of Semiconductor Devices & $.201(.053)^{* * *}$ \\
\hline Semiconductor Light Emitting Devices & $-.034(.056)$ \\
\hline Semiconductor Sense Devices & $.111(.062)^{+}$ \\
\hline Optoelectronics Devices & $-.061(.061)$ \\
\hline Optoelectronic Materials & $-.002(.045)$ \\
\hline Optoelectronic Materials and Physical & $.027(.045)$ \\
\hline Semiconductor Optic and optical fiber & $.012(.054)$ \\
\hline Advanced Optoelectronic Materials & $.049(.059)$ \\
\hline Organic Optic and Semiconductor & $-.043(.053)$ \\
\hline Material of Organic Optic & $-.025(.052)$ \\
\hline Energy Material & $.017(.051)$ \\
\hline Polymer Material and Devices & $-.136(.048)^{+}$ \\
\hline High frequency Semiconductor Devices & $-.057(.047)$ \\
\hline Subject of Optoelectronic Engineering & $.159(.053)$ \\
\hline Subject of Electrical Engineering & $-.042(.045)$ \\
\hline Calculate of Optoelectronic Devices & $.018(.052)^{*}$ \\
\hline$R^{2}$ & .704 \\
\hline Adjusted $R^{2}$ & .496 \\
\hline$F$ & $6.721^{* * *}$ \\
\hline
\end{tabular}

Note: ${ }^{+} P<0.100,{ }^{*} P<0.050,{ }^{* *} P<0.010$, and ${ }^{* * *} P<0.001$.
TABLE 11: Multiple regression analysis-cognitive domain curriculum on employability (industry sample).

\begin{tabular}{|c|c|}
\hline Course name & $\begin{array}{c}\text { Employment } \\
\beta \text { estimate } \\
\text { (standard error) }\end{array}$ \\
\hline LED Engineering Introduction & $-.100(.173)$ \\
\hline LED Lighting Application Introduction & $-.038(.161)$ \\
\hline Solar Power System Introduction & $.225(.096)^{*}$ \\
\hline Battery of Solar Power Introduction & $.034(.100)$ \\
\hline Theory of semiconductor luminous & $.102(.112)$ \\
\hline Semiconductor Memory & $-.451(.150)^{*}$ \\
\hline FPD Introduction & $.068(.127)$ \\
\hline Optoelectronics Engineering Introduction & $.005(.062)$ \\
\hline Optoelectronics Technical Introduction & $.230(.121)^{+}$ \\
\hline Optoelectronics Technology Introduction & $.172(.120)$ \\
\hline Energy Engineering Introduction & $.015(.131)$ \\
\hline Theory of Optoelectronics Instrument & $-.413(.359)$ \\
\hline Recent Optoelectronics Introduction & $.222(.127)^{+}$ \\
\hline Fourier Optics Introduction & $.014(.106)$ \\
\hline New Energy Introduction & $-.090(.129)$ \\
\hline Lighting Engineering Introduction & $.426(.125)^{* *}$ \\
\hline Optoelectronics & $-.095(.155)$ \\
\hline Wave Optic & $-.031(.121)$ \\
\hline Semiconductor Laser & $-.028(.128)$ \\
\hline Semiconductor Optic & $-.160(.113)$ \\
\hline Electromagnetics Optic & $.131(.142)$ \\
\hline Optoelectronics System & $-.114(.097)$ \\
\hline Optoelectronics Introduction & $.321(.139)^{*}$ \\
\hline Innovation of Optoelectronics & $-.168(.400)$ \\
\hline Geometrical Optic & $-.009(.260)$ \\
\hline Electronics & $-.022(.180)$ \\
\hline Electric Circuitry & $-.053(.115)$ \\
\hline Physics of Semiconductor Devices & $.005(.116)$ \\
\hline Semiconductor Light Emitting Devices & $.132(.386)$ \\
\hline Semiconductor Sense Devices & $-.245(.357)$ \\
\hline Optoelectronics Devices & $.154(.243)$ \\
\hline Optoelectronic Materials & $-.059(.159)$ \\
\hline Optoelectronic Materials and Physical & $.035(.248)$ \\
\hline Semiconductor Optic and optical fiber & $.223(.163)$ \\
\hline Advanced Optoelectronic Materials & $.016(.240)$ \\
\hline Organic Optic and Semiconductor & $-.117(.365)$ \\
\hline Material of Organic Optic & $-.399(.220)^{+}$ \\
\hline Energy Material & $.197(.328)$ \\
\hline Polymer Material and Devices & $-.036(.160)$ \\
\hline High frequency Semiconductor Devices & $.030(.181)$ \\
\hline Subject of Optoelectronic Engineering & $.825(.344)^{*}$ \\
\hline Subject of Electrical Engineering & $-.095(.300)$ \\
\hline Calculate of Optoelectronic Devices & $-.057(.104)$ \\
\hline$R^{2}$ & .615 \\
\hline Adjusted $R^{2}$ & .459 \\
\hline$F$ & $3.937^{* * *}$ \\
\hline
\end{tabular}


TABLE 12: Multiple regression analysis-skill-based curriculum on employability (university sample).

\begin{tabular}{|c|c|}
\hline Course name & $\begin{array}{c}\text { Employment } \\
\beta \text { estimate } \\
\text { (standard error) }\end{array}$ \\
\hline Design of LED Driving Circuit & $.042(.053)$ \\
\hline Design of Solar power and Lighting & $.120(.050)^{*}$ \\
\hline Semiconductor Sensor & $.002(.057)$ \\
\hline Design of Optoelectronic Devices & $.001(.056)$ \\
\hline Optoelectronic Nanometer Structure & $.135(.061)^{*}$ \\
\hline Optoelectronic Circuit Application & $.154(.054)^{+}$ \\
\hline Design of Optoelectronic Film & $.050(.055)$ \\
\hline Design of Lighting and Optoelectronic & $.021(.050)$ \\
\hline Solar Optoelectronic Technical & $.057(.045)$ \\
\hline Solar Energy Technical & $-.092(.050)^{+}$ \\
\hline Process of Semiconductor Devices & $-.152(.054)^{+}$ \\
\hline Semiconductor Package Testing and Practice & $-.009(.057)$ \\
\hline Semiconductor Design Control & $.084(.056)$ \\
\hline Semiconductor Wafer Science and Technical & $.028(.057)$ \\
\hline Semiconductor Lighting Application & $.026(.057)$ \\
\hline Optoelectronic Interaction Technical & $-.078(.060)$ \\
\hline Optoelectronic Sense Technical & $.000(.061)$ \\
\hline Optoelectronic Storage Technical & $.135(.052)^{* *}$ \\
\hline Computer aide Optoelectronic System Analysis & $-.060(.056)$ \\
\hline Semiconductor Circuit Package & $-.151(.057)^{* *}$ \\
\hline Semiconductor Circuit Process & $.157(.056)$ \\
\hline Film Engineering & $-.006(.057)$ \\
\hline Semiconductor Testing & $-.056(.050)$ \\
\hline Semiconductor and MEMS Testing & $.019(.056)$ \\
\hline Optoelectronic Engineering Testing & $.054(.051)$ \\
\hline Optoelectronic Devices and Testing & $-.032(.057)$ \\
\hline Optoelectronic Testing & $-.055(.056)^{*}$ \\
\hline Optoelectronic Translate and Driving & $-.128(.050)$ \\
\hline Optoelectronic Interference & $.015(.055)^{*}$ \\
\hline Optoelectronic Testing & $.097(.048)$ \\
\hline Light-Spot Testing & $.002(.050)^{* *}$ \\
\hline Advanced photonics Testing & $.151(.059)$ \\
\hline Introduction to Optics Testing & $-.019(.047)$ \\
\hline Optomechatronic Integration Engineering & $.074(.049)$ \\
\hline Electronic Practice & $.050(.040)$ \\
\hline$R^{2}$ & .693 \\
\hline Adjusted $R^{2}$ & .480 \\
\hline$F$ & $7.97^{* * *}$ \\
\hline
\end{tabular}

Note: ${ }^{+} P<0.100,{ }^{*} P<0.050,{ }^{* *} P<0.010$, and ${ }^{* * *} P<0.001$.

in employability $\left(R^{2}=0.596, F=4.813, P<0.001\right)$, with a significant interpretability from the industry segment. Evaluation of the regression coefficients indicates that there were only 13 courses within 35 courses, Semiconductor Sensor $(b=0.439, P<0.1)$, Design of Optoelectronic Devices $(b=0.175, P<0.1)$, Optoelectronic Nanometer
TABLE 13: Multiple regression analysis-skilled-based domain curriculum on employability (industry sample).

\begin{tabular}{|c|c|}
\hline Course name & $\begin{array}{c}\text { Employment } \\
\beta \text { estimate } \\
\text { (standard error) }\end{array}$ \\
\hline Design of LED Driving Circuit & $-.077(.088)$ \\
\hline Design of Solar power and Lighting & $.167(.129)$ \\
\hline Semiconductor Sensor & $.439(.261)^{+}$ \\
\hline Design of Optoelectronic Devices & $.175(.100)^{+}$ \\
\hline Optoelectronic Nanometer Structure & $-.837(.444)^{+}$ \\
\hline Optoelectronic Circuit Application & $-.104(.133)$ \\
\hline Design of Optoelectronic Film & $.178(.291)$ \\
\hline Design of Lighting and Optoelectronic & $-.101(.111)$ \\
\hline Solar Optoelectronic Technical & $.201(.204)$ \\
\hline Solar Energy Technical & $.156(.082)^{+}$ \\
\hline Process of Semiconductor Devices & $.195(.104)^{+}$ \\
\hline Semiconductor Package Testing and Practice & $-.083(.088)$ \\
\hline Semiconductor Design Control & $-.032(.058)$ \\
\hline Semiconductor Wafer Science and Technical & $-.132(.074)^{+}$ \\
\hline Semiconductor Lighting Application & $-.078(.130)$ \\
\hline Optoelectronic Interaction Technical & $-.075(.255)$ \\
\hline Optoelectronic Sense Technical & $-.700(.392)$ \\
\hline Optoelectronic Storage Technical & $-.053(.087)$ \\
\hline Computer aide Optoelectronic System Analysis & $.159(.083)^{+}$ \\
\hline Semiconductor Circuit Package & $-.157(.084)^{+}$ \\
\hline Semiconductor Circuit Process & $-.034(.113)$ \\
\hline Film Engineering & $-.090(.107)$ \\
\hline Semiconductor Testing & $-.129(.100)$ \\
\hline Semiconductor and MEMS Testing & $.133(.065)^{+}$ \\
\hline Optoelectronic Engineering Testing & $.067(.065)$ \\
\hline Optoelectronic Devices and Testing & $.194(.243)$ \\
\hline Optoelectronic Testing & $-.148(.077)^{+}$ \\
\hline Optoelectronic Translate and Driving & $-.049(.073)$ \\
\hline Optoelectronic Interference & $.190(.059)^{* *}$ \\
\hline Optoelectronic Testing & $.225(.302)$ \\
\hline Light-Spot Testing & $.034(.115)$ \\
\hline Advanced photonics Testing & $1.040(.485)^{*}$ \\
\hline Introduction to Optics Testing & $.008(.084)$ \\
\hline Optomechatronic Integration Engineering & $-.236(.303)$ \\
\hline Electronic Practice & $.215(.118)^{+}$ \\
\hline$R^{2}$ & .596 \\
\hline Adjusted $R^{2}$ & .472 \\
\hline$F$ & $4.813^{* * *}$ \\
\hline
\end{tabular}

Structure $(b=-0.837, P<0.1)$, Solar Energy Technical $(b=$ $0.156, P<0.1)$, Semiconductor Wafer Science and Technical $(b=-0.132, P<0.1)$, Computer Aide Optoelectronic System Analysis $(b=0.159, P<0.01)$, Semiconductor Circuit Package $(b=-0.157, P<0.1)$, Semiconductor and MEMS Testing $(b=0.133, P<0.1)$, Optoelectronic 
TABLE 14: Multiple regression analysis-affective domain curriculum on employability (university sample).

\begin{tabular}{|c|c|}
\hline Course name & $\begin{array}{c}\text { Employment } \\
\beta \text { estimate } \\
\text { (standard error) }\end{array}$ \\
\hline Industrial Safety & $-.074(.040)^{+}$ \\
\hline Semiconductor Industrial Japanese & $-.077(.034)^{*}$ \\
\hline Semiconductor Industrial English & $.053(.032)$ \\
\hline Energy Saving & $-.115(.051)^{*}$ \\
\hline Communication and Co-ordination; & $-.045(.047)$ \\
\hline Teamwork & $.082(.046)^{+}$ \\
\hline Environment Protection & $.032(.040)$ \\
\hline Industrial sustainable development & $.097(.043)^{*}$ \\
\hline Optoelectronic and Energy Industry & $.022(.049)$ \\
\hline Optoelectronic and Industry & $.184(.045)^{* * *}$ \\
\hline Tread of Optoelectronic Development & $.005(.052)$ \\
\hline Analysis Industrial and Competition & $.078(.050)$ \\
\hline Production and Operation Management & $.052(.048)$ \\
\hline Marketing Management & $.192(.044)^{* * *}$ \\
\hline Knowledge Management & $-.029(.052)$ \\
\hline Financial Management & $.112(.059)$ \\
\hline High-Tech Marketing Management & $-.156(.057)^{* *}$ \\
\hline Project Management & $.124(.058)^{*}$ \\
\hline New Energy System and Management & $-.066(.050)$ \\
\hline Forensic and Safety Management & $-.110(.053)^{*}$ \\
\hline Low-Carbon Energy Technology & $.039(.057)^{+}$ \\
\hline Technology Forecasting and Evaluation & $-.094(.053)^{+}$ \\
\hline Technology Law and IP Protection & $.162(.046)^{*}$ \\
\hline Energy Cost Analysis & $.141(.059)^{*}$ \\
\hline Intellectual Property Rights & $-.008(.057)$ \\
\hline The Standard of Green Purchasing & $.002(.049)$ \\
\hline$R^{2}$ & .700 \\
\hline Adjusted $R^{2}$ & .491 \\
\hline$F$ & $11.52^{* * *}$ \\
\hline
\end{tabular}

Note: ${ }^{+} P<0.100,{ }^{*} P<0.050,{ }^{* *} P<0.010$, and ${ }^{* * *} P<0.001$.

Testing $(b=-0.148, P<0.1)$, Optoelectronic Interference $(b=0.190, P<0.01)$, Advanced Photonics Testing $(b=1.04$, $P<0.05)$, and Electronic Practice $(b=0.215, P<0.1)$ that were statistically significant components of the model. Thus, industry and students group have a consistent idea on 7 courses within the course program in skilled-based domain.

5.4. Multiple Regression Analysis on Affective Domain Course to Employability. Results (see Table 14) show that the course program in affective domain accounted for $70.0 \%$ of the variance in employability $\left(R^{2}=0.700, F=11.52, P<\right.$ 0.001 ), with a significant interpretability from the university segment. Evaluation of the regression coefficients indicate that there were 14 courses within 26 courses including Optoelectronic and Industry $(b=0.184, P<0.001)$ and Marketing Management $(b=0.192, P<0.001)$ that were
TABLE 15: Multiple regression analysis-affective domain curriculum on employability (industry sample).

\begin{tabular}{|c|c|}
\hline Course name & $\begin{array}{c}\text { Employment } \\
\beta \text { estimate } \\
\text { (standard error) }\end{array}$ \\
\hline Industrial Safety & $-.018(.087)$ \\
\hline Semiconductor Industrial Japanese & $-.213(.072)^{*}$ \\
\hline Semiconductor Industrial English & $-.031(.096)$ \\
\hline Energy Saving & $.019(.073)$ \\
\hline Communication and Co-ordination; & $.117(.092)$ \\
\hline Teamwork & $.045(.105)$ \\
\hline Environment Protection & $.011(.059)$ \\
\hline Industrial sustainable development & $.424(.126)^{*}$ \\
\hline Optoelectronic and Energy Industry & $-.109(.072)$ \\
\hline Optoelectronic and Industry & $-.319(.128)^{*}$ \\
\hline The Tread of Optoelectronic Development & $.245(.085)^{* *}$ \\
\hline The Analysis Industrial and Competition & $.240(.106)^{*}$ \\
\hline Production and Operation Management & $.030(.062)$ \\
\hline Marketing Management & $-.111(.130)$ \\
\hline Knowledge Management & $-.114(.095)$ \\
\hline Financial Management & $.075(.103)$ \\
\hline High-Tech Marketing Management & $.056(.061)$ \\
\hline Project Management & $-.042(.063)$ \\
\hline New Energy System and Management & $.081(.051)$ \\
\hline Forensic and Safety Management & $.112(.045)^{*}$ \\
\hline Low-Carbon Energy Technology & $-.008(.096)$ \\
\hline Technology Forecasting and Evaluation & $-.030(.071)$ \\
\hline Technology Law and IP Protection & $.113(.065)^{+}$ \\
\hline Energy Cost Analysis & $.017(.079)$ \\
\hline Intellectual Property Rights & $-.053(.075)$ \\
\hline The Standard of Green Purchasing & $.061(.085)$ \\
\hline$R^{2}$ & .524 \\
\hline Adjusted $R^{2}$ & .424 \\
\hline$F$ & $5.214^{* *}$ \\
\hline
\end{tabular}

Note: ${ }^{+} P<0.100,{ }^{*} P<0.050,{ }^{* *} P<0.010$, and ${ }^{* * *} P<0.001$.

statistically significant components of the model. Results (see Table 15) show that the course program in affective domain accounted for $52.4 \%$ of the variance in employability $\left(R^{2}=0.524, F=5.214, P<0.01\right)$, with a significant interpretability from the industry segment. Evaluation of the regression coefficients indicate that there were only 7 courses within 26 courses including Tread of Optoelectronic Development $(b=0.245, P<0.01)$ and Technology Law and IP Protection $(b=0.113, P<0.1)$ that were statistically significant components of the model. In addition, industry and students group have a consistent idea on 5 courses within the course program in this domain. There are Semiconductor Industrial Japanese, Industrial Sustainable Development, Optoelectronic and Industry, Forensic and Safety Management, and Technology Law and IP Protection. This finding is also consistent with experts' suggestions while 
proceeding the expert interview method; patent application and foreign language are the foundations for employability.

From the results of multiple regression analysis, this study found the currently curriculum design in Taiwanese universities rarely fit into theory of education objectives of Bloom and Krathwohl [7, 10, 11], which includes cognitive, affective, and skill-based domains. Industry and students group also have few consistent ideas on courses within the course program. Therefore, the study attempted to provide an idea on curriculum design for the optoelectronics department according to the statistical results in order to bridge the gap between learning and practical application. First when professors design curriculum, the theory of education objectives of Bloom and Krathwohl should be followed in either domain. Second, if it is possible, expert interview method or expert review should be processed on that curriculum to make sure the courses related to the employability are instructional.

\section{Conclusion}

The study's findings can be used as critical indicators in developing optoelectronics-related school/department curriculum for colleges and universities. By relying on industry operators from the solar optoelectronics and LED industries in selecting a curriculum that caters to what the industries need, one is able to recommend to universities how to develop better curriculum planning. Finer curriculum planning at universities aligns the students' school curriculum to better meet the needs of industry, helping to shorten the industry's developmental training period. It also bridges the student to being able to directly tackle the workplace in the future. Only when a consensus on curriculum planning is reached between industry and the academic sector can the content of the teaching curriculum be bridged with industry needs, thus helping to bridge the gap between learning and practical application.

\section{Conflict of Interests}

The authors declare that there is no conflict of interests regarding the publication of this paper.

\section{Acknowledgment}

The authors are grateful for the research support from the Ministry of Science and Technology of Taiwan, under Grant nos. NSC 101-3113S-003-014- and MOST 103-3114-Y-076-28.

\section{References}

[1] A. Duff, J. Ferguson, and K. Gilmore, "Issues concerning the employment and employability of disabled people in UK accounting firms: an analysis of the views of human resource managers as employment gatekeepers," British Accounting Review, vol. 39, no. 1, pp. 15-38, 2007.

[2] A. H. Shamsuddin, A. Hunger, and A. Muchtar, "Over 10 years of cooperation between Universiti Kebangsaan Malaysia and University of Duisburg-Essen, Germany case study of the development of a fruitful partnership," Procedia-Social and Behavioral Sciences, vol. 102, pp. 11-20, 2013.

[3] A. Azapagica, S. Perdan, and D. Shallcross, "How much do engineering students know about sustainable development? The findings of an international survey and possible implications for the engineering curriculum," European Journal of Engineering Education, vol. 30, no. 1, pp. 1-19, 2005.

[4] C. J. Desha and K. C. Hargroves, "Surveying the state of higher education in energy efficiency, in Australian engineering curriculum," Journal of Cleaner Production, vol. 18, no. 7, pp. $652-658,2010$.

[5] A. G. K. Abdullah, S. H. Keat, A. Ismail, M. H. Abdullah, and M. Purba, "Mismatch between higher education and employment in Malaysian electronic industry: an analysis of the acquired and required competencies," International Journal of Engineering Education, vol. 28, no. 5, pp. 1232-1242, 2012.

[6] H. Baytiyeh, "Disparity between college preparation and career demands for graduating engineers," International Journal of Engineering Education, vol. 28, no. 5, pp. 1221-1231, 2012.

[7] B. Bloom, Taxonomy of Educational Objectives The Classification of Educational Goals; Handbook I: Cognitive Domain, David McKay, New York, NY, USA, 1956.

[8] K. R. Koedinger, A. T. Corbett, and C. Perfetti, "The knowledgelearning-instruction framework: bridging the science-practice chasm to enhance robust student learning," Cognitive Science, vol. 36, no. 5, pp. 757-798, 2012.

[9] D. R. Krathwohl and B. Bloom, Taxonomy of Educational Objectives: The Classification of Educational Goals. Handbook II: The Affective Domain, David McKay, New York, NY, USA, 1969.

[10] L. W. Anderson, D. R. Krathwohl, and P. W. Airasian, A Taxonomy for Learning, Teaching, and Assessing: A Revision of Bloom's Taxonomy of Educational Objectives, Addison Wesley Longman, New York, NY, USA, Complete edition, 2000.

[11] D. R. Krathwohl, "The taxonomy of educational objectives-its use in curriculum Building," in Defining Educational Objectives, C. M. Lindvall, Ed., University of Pittsburgh Press, Pittsburgh, $\mathrm{Pa}, \mathrm{USA}, 1964$.

[12] E. J. Simpson, The Classification of Education Objectives: Psychomotor Domain, US Department of Health, University of Illinois, 1966.

[13] C.-S. Koong, T.-I. Tang, C.-C. Wu, H.-T. Li, and C.-C. Tseng, "An investigation into effectiveness of different reflective learning strategies for learning operational software," Computers \& Education, vol. 72, pp. 167-186, 2014.

[14] C.-G. Kuo, C.-C. Chang, and C.-C. Huang, "Constructing employability indicators for enhancing the effectiveness of engineering education for the solar industry," International Journal of Photoenergy, vol. 2014, Article ID 491353, 11 pages, 2014.

[15] T. Lucas, E. Barkho, C. Rudolph, L. Zhdanova, M. Fakhouri, and L. Thompson, "Political affiliation, collective self-esteem and perceived employability of immigrants: inducing national identity polarizes host-nation employers," International Journal of Intercultural Relations, vol. 39, pp. 136-151, 2014.

[16] B. Rienties, N. Brouwer, and S. Lygo-Baker, "The effects of online professional development on higher education teachers' beliefs and intentions towards learning facilitation and technology," Teaching and Teacher Education, vol. 29, no. 1, pp. 122-131, 2013.

[17] C. Boyce and P. Neale, Conducting In-Depth Interviews: A Guide for Designing and Conducting In-Depth Interviews for Evaluation Input, Pathfinder, Watertown, Mass, USA, 2006. 
[18] C. Huang, H. Chang, and S. Henderson, "Knowledge transfer barriers between research and development and marketing groups within Taiwanese small-and medium-sized enterprise high-technology new product development teams," Human Factors and Ergonomics In Manufacturing, vol. 18, no. 6, pp. 621657, 2008.

[19] A. Anastasi, Psychological Testing, Prentice Hall, Upper Saddle River, NJ, USA, 6th edition, 1988.

[20] R. K. McKinley, T. Manku-Scott, A. M. Hastings, D. P. French, and R. Baker, "Reliability and validity of a new measure of patient satisfaction with out of hours primary medical care in the United Kingdom: development of a patient questionnaire," British Medical Journal, vol. 314, no. 7075, pp. 193-198, 1997.

[21] J. Cohen, P. Cohen, S. G. West, and L. S. Aiken, Applied Multiple Regression/Correlation Analysis for the Behavioral Sciences, Routledge, New York, NY, USA, 3rd edition, 2013.

[22] E. T. Lee and J. W. Wang, Statistical Methods for Survival Data Analysis, John Wiley \& Sons, New York, NY, USA, 4th edition, 2013. 

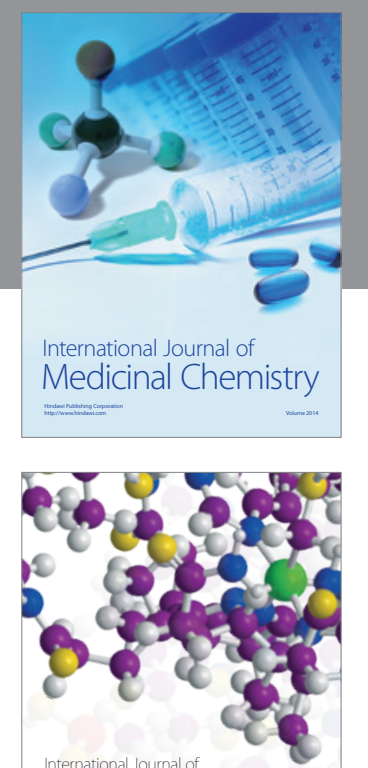

\section{Carbohydrate} Chemistry

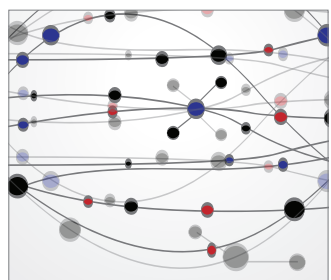

The Scientific World Journal
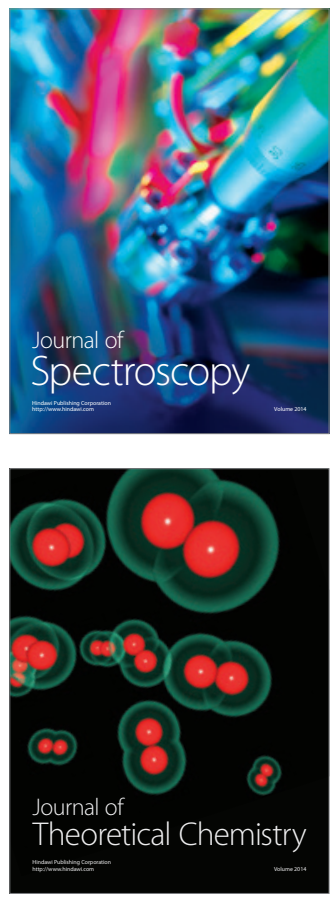
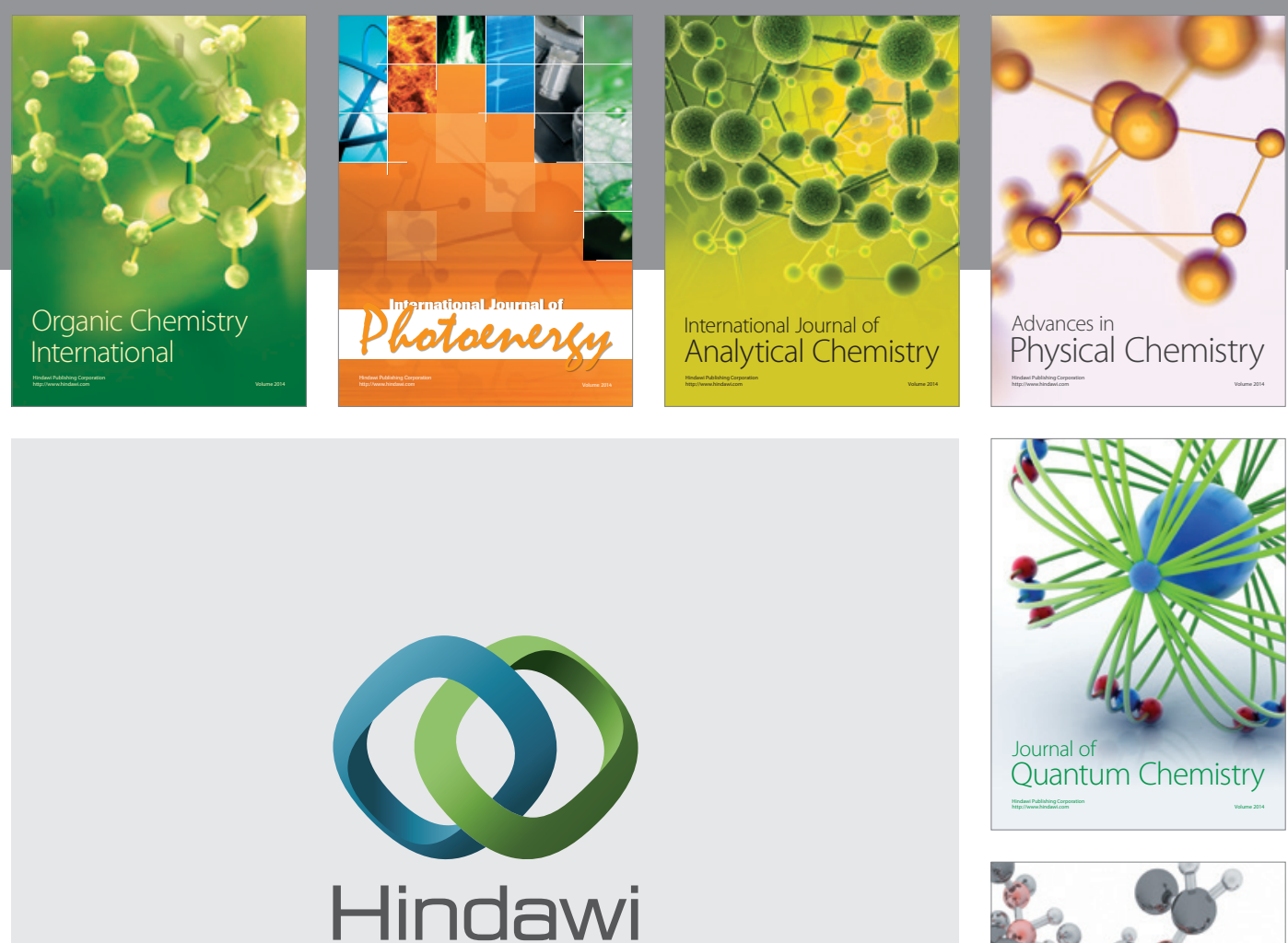

Submit your manuscripts at

http://www.hindawi.com

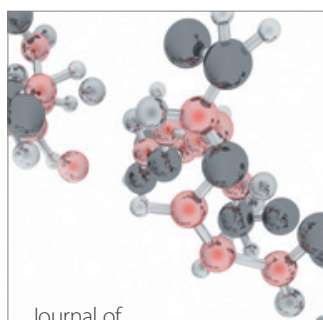

Analytical Methods

in Chemistry

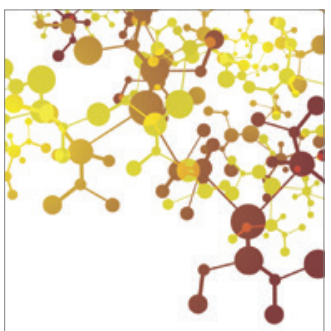

Journal of

Applied Chemistry

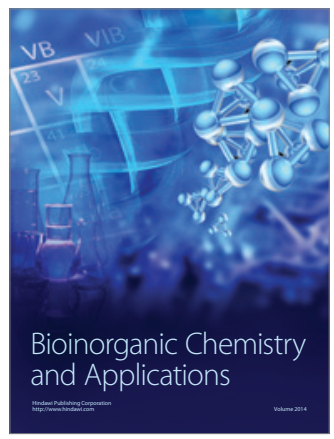

Inorganic Chemistry
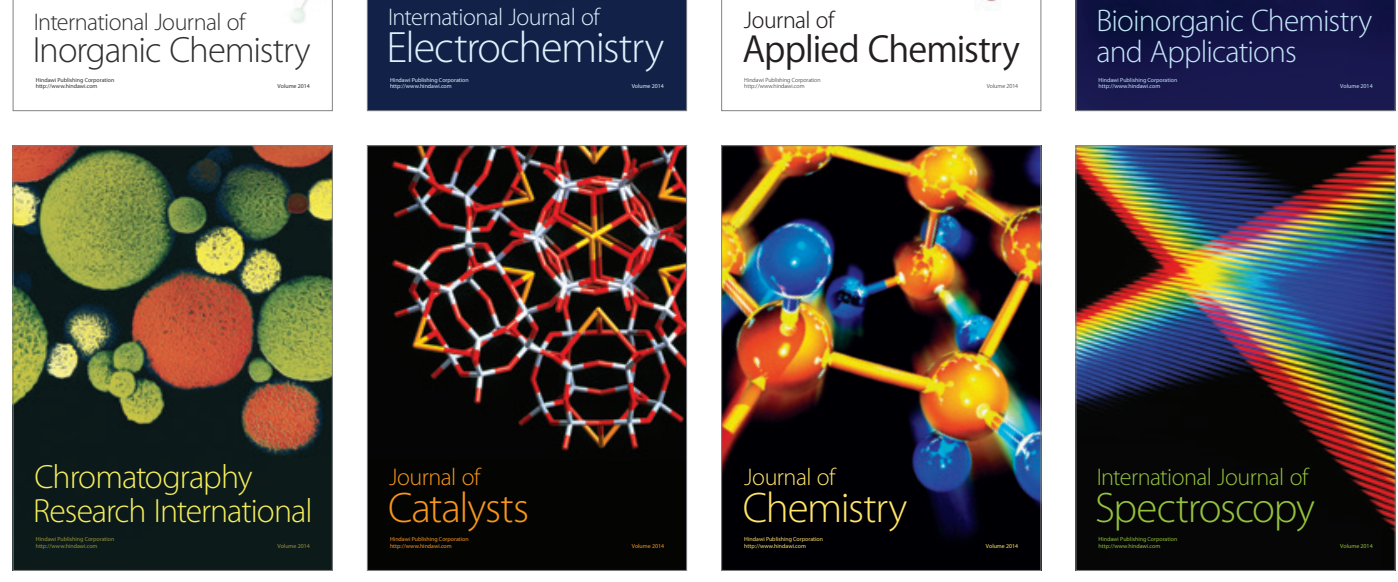